\title{
Sensor Module Based on the Wireless Sensor Network for the Dynamic Stress on the Flexible Object with Large Deformation
}

\author{
Jinhui Zhao, Yi Zhuang, Jingjing Gu, Yan Xu, and Jian Sun \\ College of Computer Science and Technology, Nanjing University of Aeronautics and Astronautics, Nanjing 210016, China \\ Correspondence should be addressed to Yi Zhuang; zy16@nuaa.edu.cn
}

Received 14 December 2015; Revised 1 April 2016; Accepted 19 April 2016

Academic Editor: Alberto J. Palma

Copyright (C) 2016 Jinhui Zhao et al. This is an open access article distributed under the Creative Commons Attribution License, which permits unrestricted use, distribution, and reproduction in any medium, provided the original work is properly cited.

\begin{abstract}
When we are measuring the dynamic stress on flexible objects with large deformation, for example, the parachute, the morphologic structure of the tested objects changes rapidly and sharply, and the measurement is conducted in a poor and variable environment. Traditional measuring methods cannot ensure credibility, repeatability, and high precision of the test. This paper introduces stress sensor module based on the wireless sensor network for the flexible objects with large deformation. In this paper, the wireless sensor network works as the signal transmitting carrier and the $\Omega$ sensor is improved. In addition, the paper further studies the effect of module deployment on the flexible objects with large deformation and the effect of experiment environment on the sensor test. Finally, the compensation method is proposed and measurement reliability is improved. The performance experiments of the sensor verify the availability and repeatability of the dynamic sensor module. The drop experiment of the small parachute and the wind tunnel experiment prove that the sensor module can effectively measure the stress on the flexible object with large deformation and the results accord with the parachute canopy stress rule.
\end{abstract}

\section{Introduction}

With the development of modern industrial technology, the flexible fabric with large deformation has been widely used. However, it is difficult to measure and analyze its stress when it is working. Deformation of the flexible object happens instantly at a high speed. During this process, the material shape changes dramatically. The mechanical distribution characteristics, material strength, and elongation are quite different from those in the static state. At present, no method can calculate the exact stress in the deformation process. The analysis and verification in the designing process of the parachute mainly depend on experiments [1-5]. However, current measurement methods are not suitable for large deformation and can be used only for qualitative analyses [6].

Current measurement methods mainly use the wired transmit of signals. The wire deployment will affect the shape of the flexible object. In particular, for big-size flexible objects, the deployment becomes more difficult and the overlong wire may weaken the signals and affect the measure effects. As a distributed sensor network, the terminal of the wireless sensor network (WSN) is a type of sensor that can perceive and inspect the outside world. As sensors in the WSN communicate in the wireless mode, the network settings are flexible and device positions can be changed at any time. Using the WSN as the transmitting carrier of signals can effectively reduce the sensor layout impact on the tested object in the wired mode [7]. Besides, the signal transmitting distance in the WSN can reach thousands of meters, which can deal with the distance restrictions during the wired transmission.

Against these problems, this paper proposes $\Omega$-type sensor module and conducts an in-depth study and analysis of various factors in the measurement. Besides, a compensation method is proposed to accurately measure the working process of the flexible fabric with large deformation.

\section{Related Work}

Over the past years, researchers have studied the dynamic stress on the flexible objects with large deformation. In the 1960s, the US army measured the pressure on the parachute canopy surface with a strain pressure sensor $[8,9]$. However, 
TABLE 1: Comparisons among current test methods.

\begin{tabular}{|c|c|c|c|c|c|}
\hline Sensor type & Weight (g) & Core idea & $\begin{array}{c}\text { Influence of layout } \\
\text { technique }\end{array}$ & $\begin{array}{l}\text { Influence of } \\
\text { temperature }\end{array}$ & Experiment type \\
\hline $\begin{array}{l}\text { Strain pressure } \\
\text { sensor [8] }\end{array}$ & 5.67 & $\begin{array}{l}\text { Stress change on the } \\
\text { fabric surface }\end{array}$ & $\begin{array}{l}\text { Great but not } \\
\text { handled }\end{array}$ & $\begin{array}{c}\text { Temperature } \\
\text { influence considered } \\
\text { and half-bridge } \\
\text { temperature } \\
\text { compensated }\end{array}$ & $\begin{array}{l}\text { Low-speed wind } \\
\text { tunnel experiment } \\
\text { and drop } \\
\text { experiment }\end{array}$ \\
\hline $\begin{array}{l}\Omega \text {-type sensor } \\
{[10]}\end{array}$ & 2.7 & $\begin{array}{l}\text { Good structure for } \\
\text { stress transmitting }\end{array}$ & $\begin{array}{c}\text { Relatively great but } \\
\text { not handled }\end{array}$ & $\begin{array}{c}\text { Temperature } \\
\text { influence considered } \\
\text { and strain gauge } \\
\text { compensated }\end{array}$ & $\begin{array}{l}\text { Drop experiment } \\
\text { and low-speed } \\
\text { wind tunnel } \\
\text { experiment }\end{array}$ \\
\hline $\begin{array}{l}\mathrm{CPC} \text { composite } \\
\text { material sensor } \\
{[1,11]}\end{array}$ & $\begin{array}{l}\leq 1.2 \\
\text { The storage device is } \\
\text { deployed on the } \\
\text { surface of the } \\
\text { parachute } \\
\text { Weight: } 10 \mathrm{~g}\end{array}$ & $\begin{array}{l}\text { Stress change on the } \\
\text { fabric surface }\end{array}$ & $\begin{array}{l}\text { Limited and } \\
\text { compensated on } \\
\text { the coating } \\
\text { thickness }\end{array}$ & $\begin{array}{l}\text { Not compensated; } \\
\text { subzero temperature } \\
\text { not analyzed }\end{array}$ & Drop experiment \\
\hline $\begin{array}{l}\text { Fiber sensor } \\
{[12,13]}\end{array}$ & Uncertain & $\begin{array}{c}\text { Stress change tested } \\
\text { by fiber deformation } \\
\text { level }\end{array}$ & $\begin{array}{l}\text { Limited and not } \\
\text { handled }\end{array}$ & $\begin{array}{c}\text { Temperature } \\
\text { influence considered } \\
\text { and strain gauge } \\
\text { compensated }\end{array}$ & Drop experiment \\
\hline $\begin{array}{l}\text { Improved } \Omega \\
\text { type sensor } \\
\text { module (IOS) }\end{array}$ & 2.2 & $\begin{array}{c}\text { Compensation on the } \\
\text { influencing during } \\
\text { the test }\end{array}$ & $\begin{array}{c}\text { There is influence } \\
\text { but it is } \\
\text { compensated }\end{array}$ & $\begin{array}{c}\text { Temperature } \\
\text { influence considered } \\
\text { and full-bridge } \\
\text { temperature } \\
\text { compensated }\end{array}$ & $\begin{array}{l}\text { Drop experiment } \\
\text { and low-speed } \\
\text { wind tunnel } \\
\text { experiment }\end{array}$ \\
\hline
\end{tabular}

limited by the sensor deployment and sensor capabilities, the experimental result could not satisfy the requirement of accuracy. In the 1970s, for the first time, NASA proposed that the parachute canopy stress could be measured using the wired sensor. During the experiment, $\Omega$ sensor was adopted to measure the parachute canopy fabric. However, due to technology limitations, the experiment just conducted a qualitative analysis of deployment of the parachute canopy under the air flow [10].

Since 2007, French Textile Materials and Engineering Laboratory proposed a CPC composite material sensor to measure flexible objects. This method provided a new idea. However, because of the unsatisfactory ductility of the material, they just conducted the static test [11]. Till 2010, the laboratory made some improvements in the CPC composite material sensor, analyzed the temperature influence, sensor aging, and repeatability, and implemented a small-scale drop test. However, material ductility was still a problem [1].

Since 2009, NASA has been using the fiber sensor to measure the parachute canopy stress. However, due to the limited ductility of fiber materials, the experiment can only measure small deformation. In 2010, Beijing Institute of Space Machinery and Electronics (BISME) improved the fiber sensor and applied it to the test of parachute canopy. However, due to the problems of cross sensitivity of temperature and strain and poor antishear ability, the fiber sensor could not satisfy the requirement of wind tunnel experiment [12].

In conclusion, current researches have provided multiple solutions to the measurement of stress on the flexible object with large deformation and made some progress. However, problems of limited ductility and layout technique as well as environmental factors which can affect the experiment still exist. On account of all the mentioned difficulties and deficiencies of technology, this paper proposes a sensor module based on the wireless sensor network for the stress on the flexible object with large deformation. Through the improved $\Omega$-type sensor, the fabric stress change can be well detected and the data can be transmitted through the wireless sensor network. Therefore, the data will be compensated and studied. The parachute is taken as a typical application for the experiment and verification. The performance comparison among current methods and the sensor module is shown in Table 1. In the table, the "drop experiment" means real opening from the bag to stabilized descent.

\section{Design of the Sensor Module}

The measurement of the stress on the flexible object with large deformation can be represented by the converting process from the stress signal to electrical signal. To ensure correctness and accuracy, the sensor should possess a good stress transmitting structure to reduce stress loss during the transmitting process. Then the sensor will convert the stress signal and eliminate the external influence and interference on the sensor and try to amplify the signal to make it easier to be received, processed, and delivered. Hence, the sensor module for the flexible object with large deformation is proposed. The model consists of the $\Omega$ sensor part and auxiliary circuit part. The $\Omega$ sensor part comprises the stress transmitting structure, which is the $\Omega$-type media and 


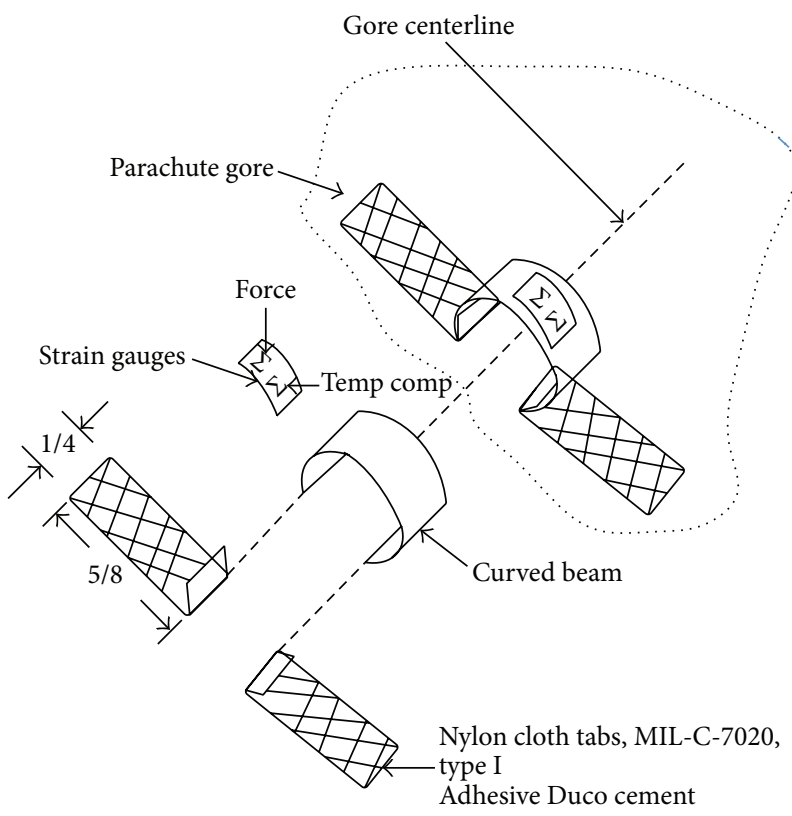

(a)

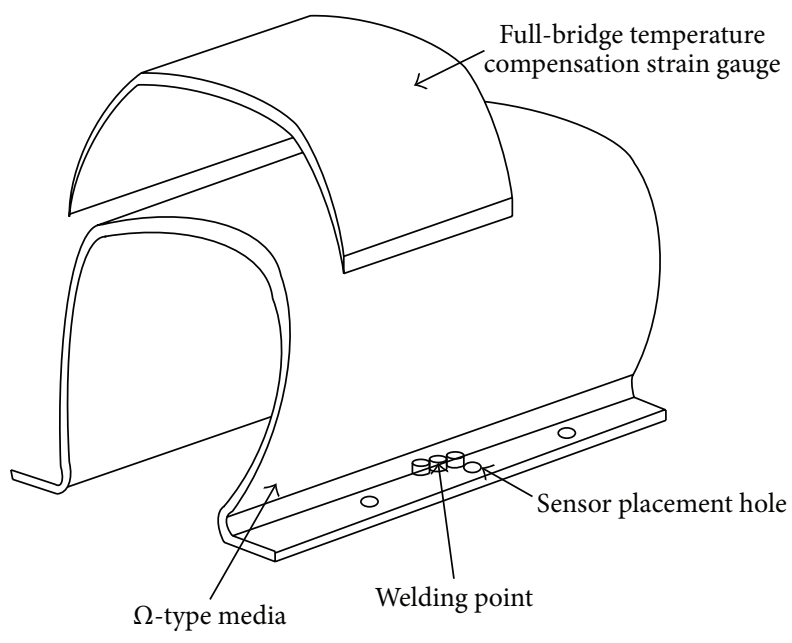

(b)

Figure 1: (a) C-type structure [7]. (b) $\Omega$-type structure [10].

stress perception part (full-bridge temperature compensation strain gauge). The full-bridge temperature compensation strain gauge deployed on the media perceives the stress change and converts it to the electrical signal. The auxiliary circuit consists of the conditioning regulation circuit and storage/distribution circuit. The regulation circuit amplifies the signal and regulates the filtering. The storage/distribution circuit saves or transmits the conditioning signal. Through this, the dynamic data of the flexible object can be collected.

3.1. Design of the Stress Sensor. At present, there are two types of structures for the measurement sensor, including the rigid structure and fiber structure. The fiber sensor cannot obtain the overall stress information due to its fragility. As shown in Figure 1(a), the sensor in [7] is a typical rigid structure sensor, which can satisfy the basic measurement requirements. However, in this sensor, fabric is selected as the joint between the C-type part and the tested object, leading to a big loss of stress in the joint structure. Besides, manual consistency and repeatability are two problems for the C-type part. Aimed at this problem, this paper improves the C-type sensor in [7] from the following aspects: (1) the connecting mode between the bottom fabric and the C-type part is changed to the integrated $\Omega$ type to reduce stress loss in the transmitting period; (2) spring steel is used. The compressive strength of the structure is more than 1 ton, as shown in Figure 1(b).

To select a proper strain gauge, environmental influence, especially the temperature when the flexible fabric is working, should be considered. The full-bridge temperature strain gauge can reduce influence of temperature changes on the sensor strain so that the measurement accuracy can be improved greatly.
Different adhesion agents are used to bind the strain gauge with the $\Omega$-type media and the $\Omega$-type media with the tested fabric. After that, threads are used to fix them through the layout holes.

3.2. Design of Auxiliary Circuit. In the measurement of the stress on the flexible object with large deformation, the voltage signal collected by the strain gauge is as weak as the $\mathrm{mV}$ level and noises are easily produced. Therefore, a conditioning circuit is designed to regulate the signal. Current measurement methods all adopt the wired mode. However, in a real working environment, deployment of the transmission wire may affect the test and a long wire may result in the loss of signal transmission in the measurement. As a result, a storage/distribution circuit is designed. In terms of the structure, it is stacked together with the regulation circuit. In terms of the function, it transmits the data in the wireless mode. Figure 2 shows the design of the auxiliary circuit.

In order to improve the quality of the voltage signal collected by the sensor, the following steps are designed.

Step 1. $\mathrm{mV}$ signals are amplified to the $\mathrm{V}$ level when they are crossing the double amplifying circuit, which can strengthen the damage-proof and perception capabilities of the signals.

Step 2. After signals enter the signal preprocessing circuit, they are processed with filter modulation and rectification. The filtering process can effectively eliminate the noise in the signal, while modulation and rectification can make signals easier to process.

Step 3. The processed signals enter the compensation and voltage circuit, where they are kept within the strength scope 


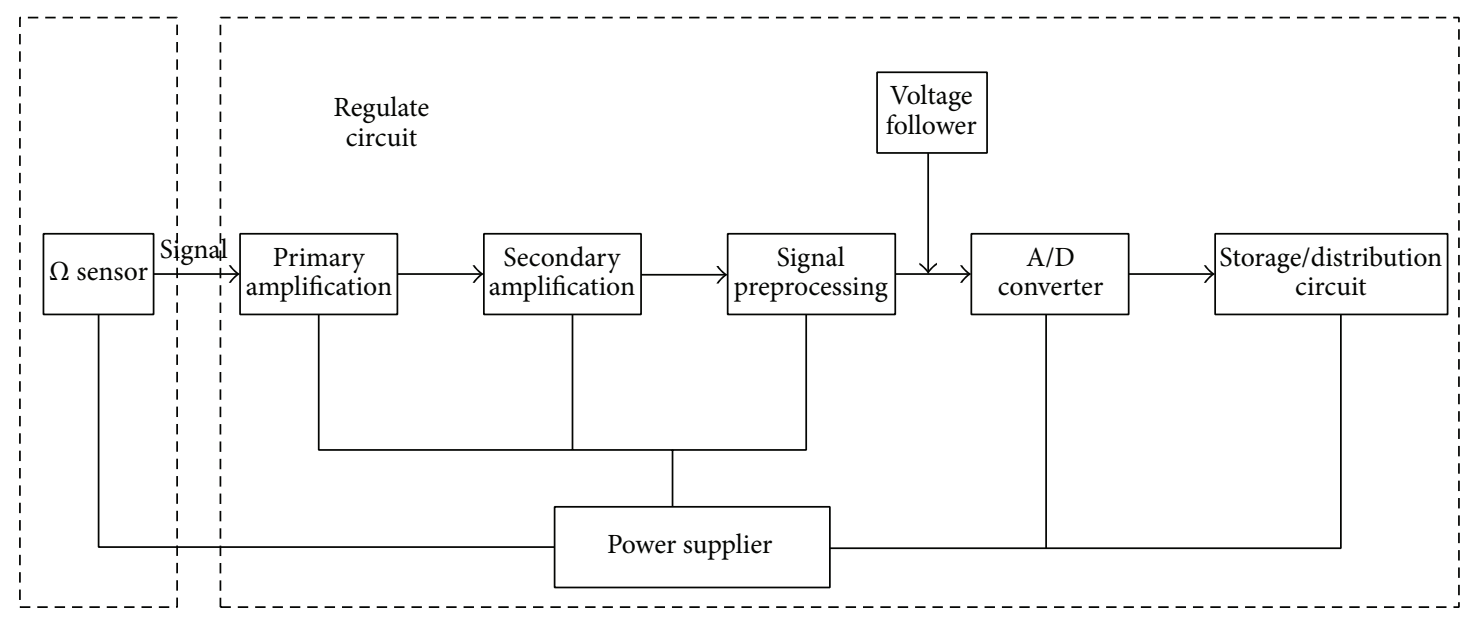

FIGURE 2: Auxiliary circuit of the sensor module.

set at the A/D convert circuit. Through this step, the loss in the transmitting process will be effectively compensated for.

Step 4. The simulated signals are converted to digital signals through the A/D converter and saved or delivered according to the final demand.

The signal auxiliary circuit mentioned above can effectively improve the quality of signals, reduce the loss of signals during the transmitting process, and make it easier to get the processed signals in subsequent circuits.

3.3. Deployment and Application of the Sensor Module. The measurement sensor module for the stress on the flexible object with large deformation consists of the improved $\Omega$ sensor and auxiliary circuit. Since the $\Omega$ sensor is small and light, it can be deployed directly on the flexible fabric surface. The $\Omega$ sensor transmits the data collected by the sensor to the auxiliary circuit in the wired mode. The auxiliary circuit can be deployed on the parachute cord and reinforcing band or deployed as a suspension. This circuit can transmit the data in the wireless mode to the ground base station. In our experiment, the deployment of the parachute is under real opening from the bag to stabilized descent. Figure 3 shows the typical measurement state.

\section{Compensation of the Sensor}

When working, the sensor is easily affected by various factors and the measuring results may be not accurate. The factors can be the three aspects as follows:

(1) The shape of the flexible object changes rapidly, which may affect data accuracy. Current measurement methods do not consider the dramatic change of the length and width in the changing process of the flexible object.

(2) The sensor deployment also affects the result. When the sensor is deployed, adhesive agents and needlework are required for fastening, which also has some impacts on the fabric.

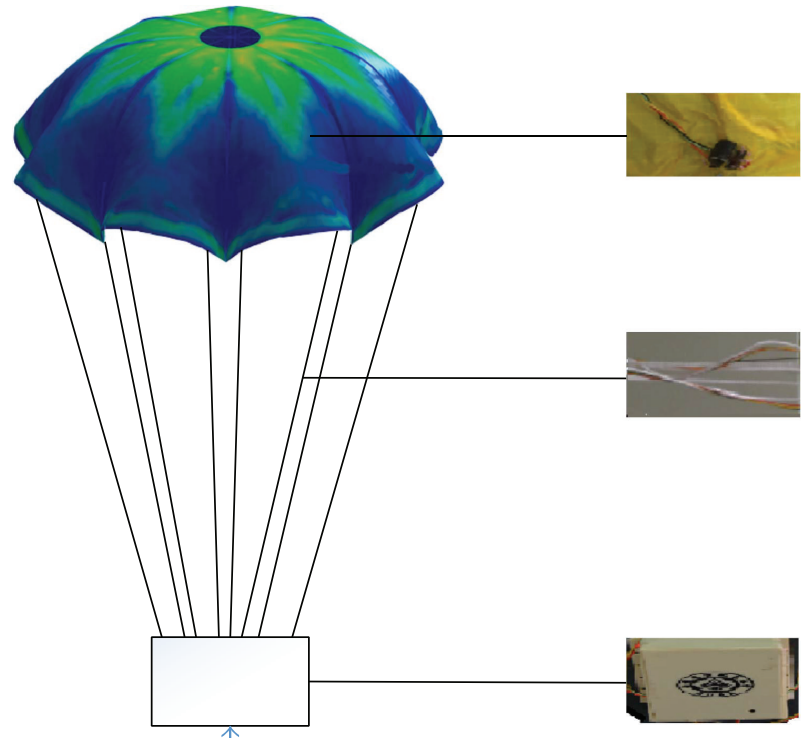

FIGURE 3: Typical measurement state of stress sensor module.

(3) Environmental changes, especially temperature changes in the real environment, also affect the measurement of the sensor. Current measurement methods mainly deal with this factor using the hardware. This research deals with the temperature impact using the full-bridge temperature compensation strain gauge.

4.1. Influences of Fabric Scalability on Stress Measurement. The static stress on materials can be measured with the universal material testing machine. The sensor is attached to the tested sample surface. The tested sample is put vertically on the furniture of the tensile machine and the test can be conducted through the stretch of the material. The parachute canopy is a typical flexible fabric with large deformation flexible fabric. With the stress, it will change in the zonal and radial directions. To study the influences of the parachute canopy fabric scalability on the measurement result of the 


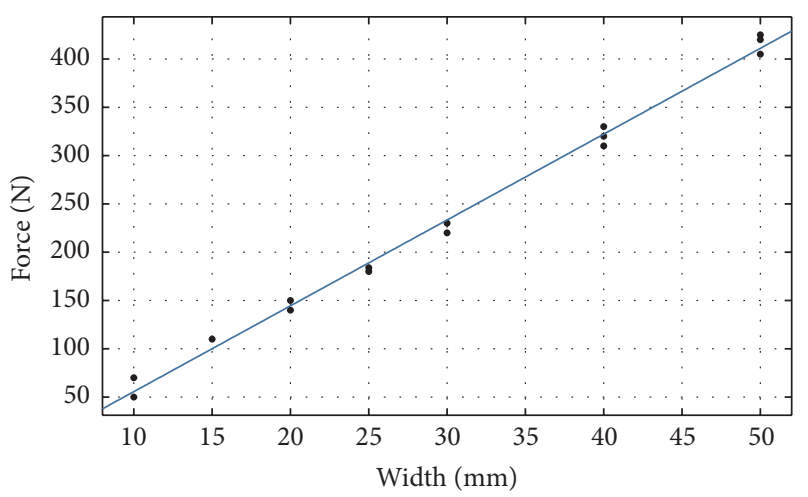

Figure 4: Influences of different widths on the parachute canopy material stress.

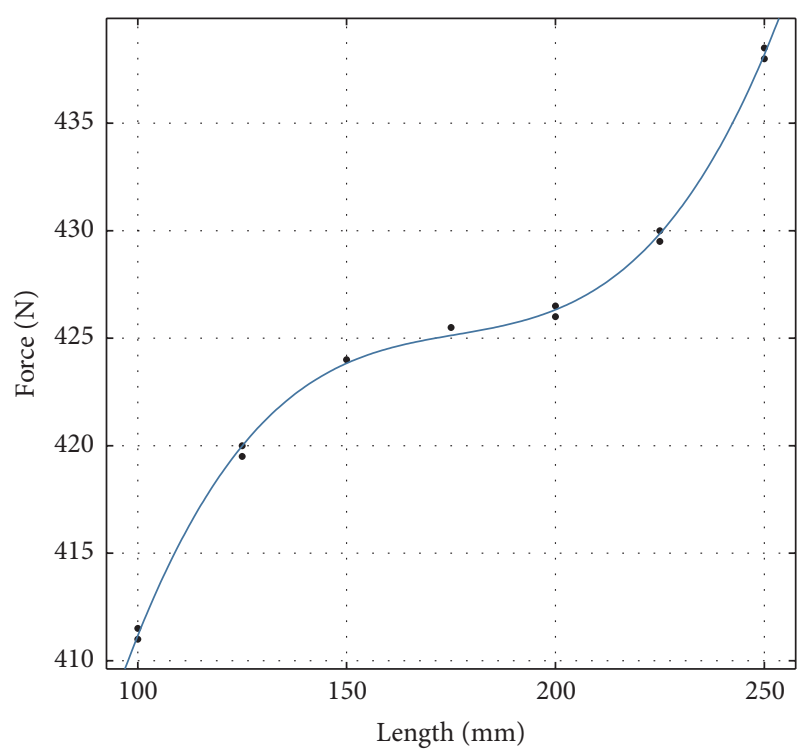

FIGURE 5: Influences of different lengths on the parachute canopy material stress.

sensor, tension experiments are conducted for the parachute canopy fabric with different sizes and the results are analyzed.

544 nylon silk is a commonly used material for the parachute canopy. With the length below $20 \mathrm{~cm}$, pieces of width at an interval of $5 \mathrm{~mm}$ are selected for the experiment. Tension tests are conducted for them with a universal material testing machine. The stretch scope starts from $0 \mathrm{~N}$ until the stress that breaks the sample. Each width is tested nine times. Figure 4 shows the measurement data.

As shown in Figure 5, the stress performance of the parachute canopy material has a linear relationship with different widths of the material. $F_{1}$ stands for the stress within the sensor measuring range, $F_{2}$ stands for the stress on the overall material, $x_{2}$ is the sensor width, and $x_{3}$ is the overall width of the sample fabric. The relationship of sensors measure stress and fabric overall stress is shown in the following formula:

$$
\frac{F_{1}}{F_{2}}=\frac{x_{2}}{x_{3}}
$$

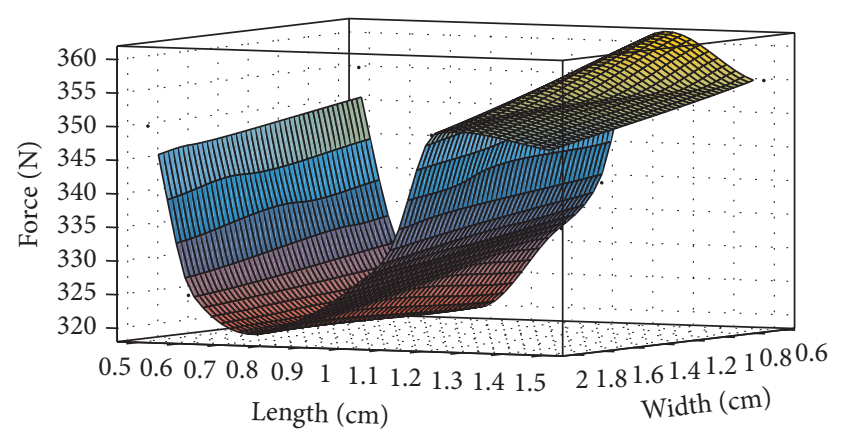

FIGURE 6: Influences of different adhesive lengths and widths on the parachute canopy material stress.

Take 544 nylon silk as an example. With the width below $5 \mathrm{~cm}$, pieces of length at an interval of $5 \mathrm{~cm}$ are selected for the testing sample. Tension tests are conducted for them with a universal material testing machine. The stretch scope starts from $0 \mathrm{~N}$ until the stress that breaks the sample. Each width is tested nine times. Figure 5 shows the measurement data.

As shown in Figure 6, through the fitting of the measurement data, the cubic expression can depict the measurement data. Set the fact that the stress in the tensile process is three times b-spline $B_{3}$, the length of the sensor is $x_{1}$, and fabric edge area is $s$. Then the stress in a small sensor area can be expressed as the following formula:

$$
F_{1}=\int_{0}^{x_{1}} B_{3} d s .
$$

4.2. Influences of Adhesive Agents on Parachute Canopy Material Stress. The use of adhesive agents will change features of the parachute canopy material and the way of using adhesive agents will also affect the stress on materials. As tools of fixing coating thickness can be used in adhesive work, this paper only studies the influences of width and length. Samples with the same effective length of $20 \mathrm{~cm}$ and effective width of $5 \mathrm{~cm}$ are selected. Gluing of different widths and lengths is conducted based on the parachute canopy material. Tension tests are conducted for them with a universal material testing machine. The stretch scope starts from $0 \mathrm{~N}$ until the stress that breaks the sample. Figure 6 shows the measurement data.

After groups of experiments, the stress features of the fabric change with different widths and lengths of the adhesive. Therefore, the width and length combination of adhesive agent that has the minimum influence on the sample is selected as the adhesive agent combination for the experiment. As shown in Figure 7, the influence on the parachute canopy fabric is the smallest (not exceeding 2\%) when the adhesive length is $1.2 \mathrm{~cm}$ and the adhesive width is $0.6 \mathrm{~cm}$.

4.3. Influence of the Temperature on the Sensor. In the actual working process of the parachute, the environmental temperature changes a lot when the parachute drops from a high altitude. Therefore, it is necessary to study the influence of the temperature change on the sensor and deal with the 


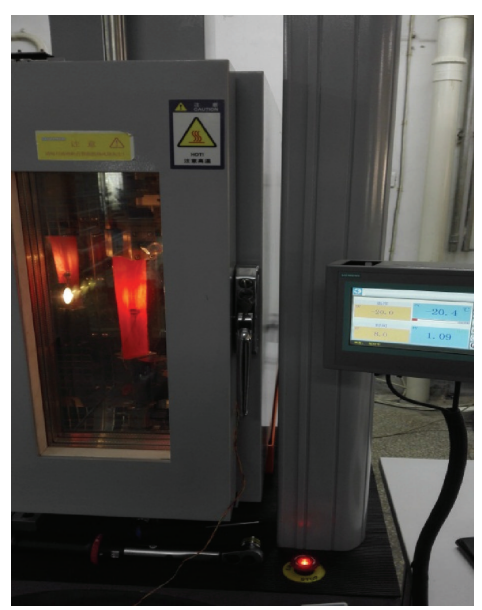

FIGURE 7: Stretch experiment by high and low temperature universal material testing machine.

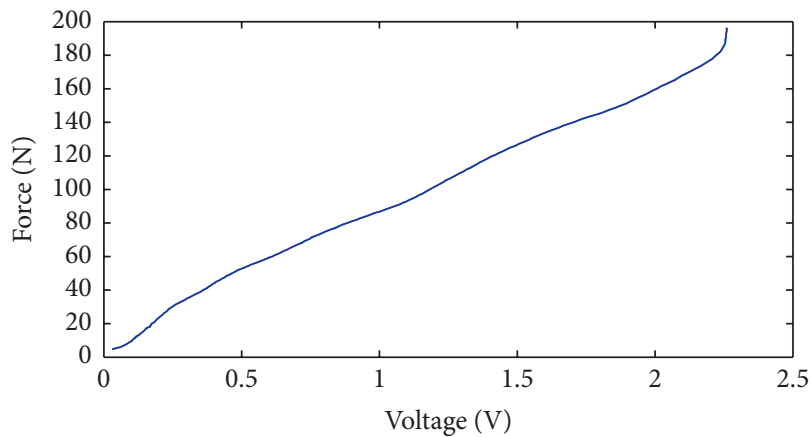

- Calibration data — Real data

(a) $-10^{\circ} \mathrm{C} 544$ silk

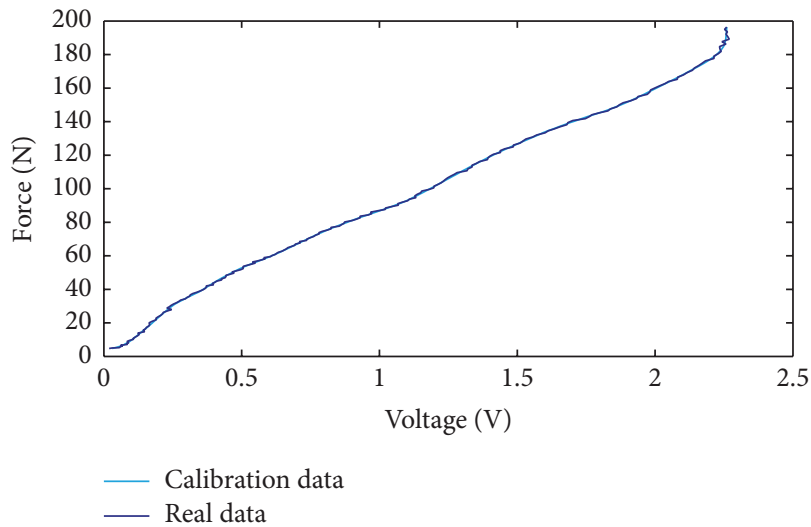

(c) $45^{\circ} \mathrm{C} 544$ silk

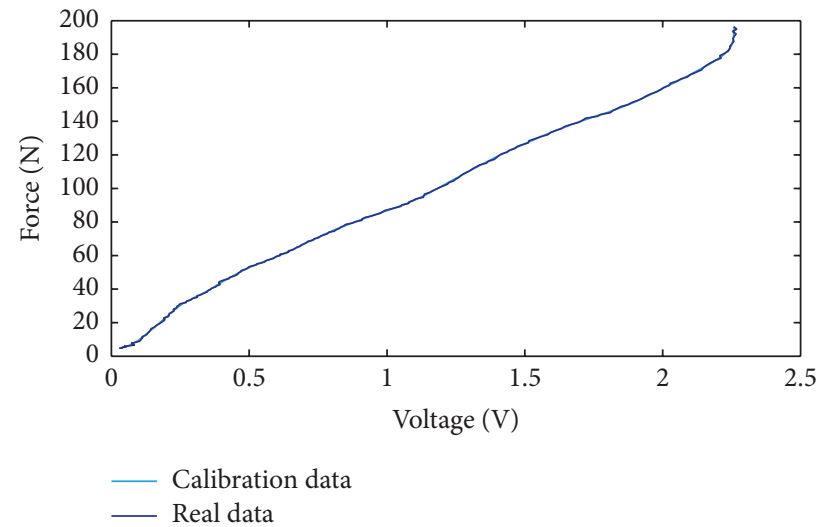

(b) $25^{\circ} \mathrm{C} 544$ silk

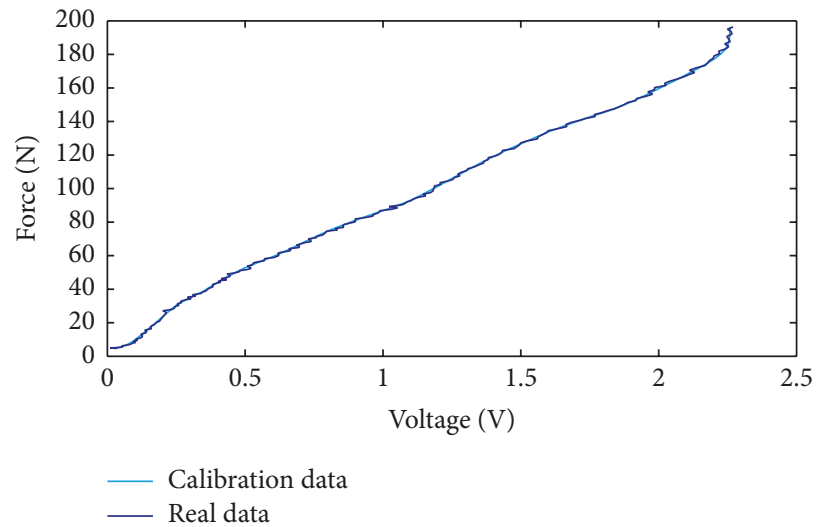

(d) $65^{\circ} \mathrm{C}$ K59225 silk

FIGURE 8: Analysis of measured data under different environments for different fabrics.

influence. A piece of 544 nylon silk with an effective length of $20 \mathrm{~cm}$ and width of $5 \mathrm{~cm}$ is selected as the sample. The sensor is put in the middle of the tested fabric, with the adhesive width of $0.6 \mathrm{~cm}$ and the adhesive length of $1.2 \mathrm{~cm}$. Then stretch experiments are carried out under different setting temperatures by using a high and low temperature universal material testing machine to observe the influence of temperature on the sensor. Figure 7 shows the experiment.
The comparison between the real data and rating data under different temperatures for different fabric is shown in Figure 8.

As shown in Figure 9, the temperature has a certain influence on the sensor in the scope of $-20^{\circ} \mathrm{C}$ to $65^{\circ} \mathrm{C}$, but it kept within the scope of $1 \%$. Through the accumulation of data, temperature compensation can be introduced into the data processing in the final test. In [14], where the 


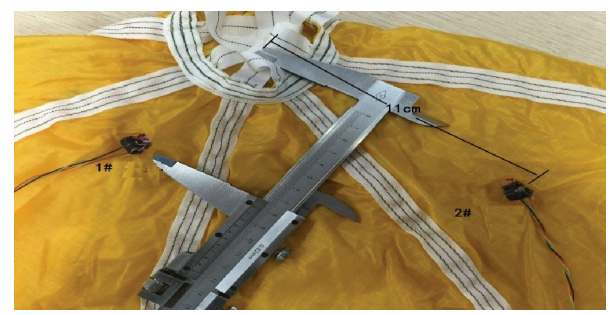

FIGURE 9: Deployment of 544 circle flat parachute sensor module.

temperature compensation relationship is introduced, the BP neural network can solve the problem of temperature compensation, which can be expressed as (3). $F_{r}$ stands for the actual measured stress, $F_{s}$ stands for the final stress after compensation processing, $F_{(t)}$ stands for the compensation value after using the BP neural network [15], and $t$ stands for the temperature:

$$
\begin{gathered}
F_{s}=F_{r}+F_{(t)}, \\
F_{(t)}=\operatorname{BP}(t) .
\end{gathered}
$$

4.4. Compensation of the Sensor. In current measurement methods, the measurement is affected by various factors. Although there are experiments about the factors, no research has studied the reasonable compensation for them. By taking advantage of the accumulated experimental data, compensation is calculated based on the direct measurement results of the sensor to obtain reliable data. The compensation equations are shown as

$$
F=\int_{0}^{x_{1}} \operatorname{BS}(v) d s * \frac{x_{2}}{x_{3}} * \frac{k \sigma_{\max }-\theta}{\sigma}+F_{(t)} .
$$

According to the experimental results, the correspondence of the voltage signal and stress collected by the sensor can be expressed by the three degree B-spline curves. In the expression, $v$ refers to the voltage value collected by the sensor; BS $(v)$ stands for the related stress value; $s$ is the cross section area; $x_{1}$ is the sensor length; $x_{2}$ is the sensor width; $x_{3}$ is the tested fabric width; $\left(k \sigma_{\max }-\theta\right) / \sigma$ refers to the stress concentration factor; $k$ stands for the distribution function ( $k$ is a fixed value in a certain environment); $\theta$ refers to the adhesive influencing factor; and $F_{(t)}$ is the temperature comprehension equation.

\section{Experiment Design of the Sensor Performance}

5.1. Measure the Degree of Aging. In order to the test stability of the sensor module, the module is placed horizontally in the constant temperature and humidity box to avoid any external force. Every ten days, the sensor is taken out. A piece of 544 nylon silk with an effective length of $20 \mathrm{~cm}$ and width of $5 \mathrm{~cm}$ is selected as the sample. Then the sensor is put in the middle of the tested fabric, with the adhesive width of $0.6 \mathrm{~cm}$ and the adhesive length of $1.2 \mathrm{~cm}$. Set the stretching speed at
$100 \mathrm{~mm} / \mathrm{min}$ and stretching scope between 0 to $200 \mathrm{~N}$. After that, tension tests are conducted with a universal material testing machine for 80 days and the data will be recorded.

5.2. Repeated Measurement Experiments. In order to test the fatigue resistance of the sensor module, repeated tension tests are conducted for the module. The sensor is put on a piece of flexible fabric with the length of $20 \mathrm{~cm}$ and width of $5 \mathrm{~cm}$. Set the stretching speed at $100 \mathrm{~mm} / \mathrm{min}$ and stretching scope between 0 and $200 \mathrm{~N}$ and repeat the experiments constantly in the same experimental environment. Repeat the experiment five times and record the experiment data.

5.3. Drop Experiment. The drop experiment is under real opening from the bag to stabilized descent. The circle flat parachute is selected for the drop experiment. The parachute canopy is made of 544 nylon silk and reinforcing band of 15150 A nylon silk ribbon. The size of the canopy is $1 \mathrm{~m}^{2}$ and the parachute rope is $1 \mathrm{~m}$. The drop height is $25 \mathrm{~m}$ in a normal external environment with the horizontal wind speed lower than $0.2 \mathrm{~m} / \mathrm{s}$. A $10 \mathrm{~kg}$ object is attached to the tested parachute.

5.4. Wind Tunnel Experiment. The experiment uses the same parachute type for the drop experiment. The wind tunnel is an $\mathrm{NH} 2$ all-steel structure closed jet return low-speed wind tunnel with the test section length of $6 \mathrm{~m}$, width of $3 \mathrm{~m}$ and height of $2.5 \mathrm{~m}$, and wind speed of $30 \mathrm{~m} / \mathrm{s}$. The experiment employs a tower-type six-component mechanical strain external balance with $0.2 \%$ accuracy, $40^{\circ} /-30^{\circ}$ angle of attack, and $\pm 45^{\circ}$ sideslip. The connector of the parachute balance can be rotated.

The 544 nylon silk circle flat parachute sensor is deployed at two different latitudes. Sensor ID1\# and sensor ID3\# are $8 \mathrm{~cm}$ away from the center hole and sensor ID2\# and sensor ID3\# are $11 \mathrm{~cm}$ away from the center hole. Figure 9 shows the detailed deployment.

Process for the parachute packing and installation parachute opening device in the wind tunnel experiment is shown as follows.

Step 1. Fold the parachute. The parachute can be folded according to the parachute panel. After being folded, the two panels should be symmetrical on the reinforcing band.

Step 2. Fold the parachute cord into the middle of the parachute, fold the symmetrical parachute panels, and then fold the panels along the parachute cord.

Step 3. Pack the parachute, parachute cord, and WSN acquisition nodes into the parachute bag. Install the parachute bag onto the rotating connector of the parachute balance.

Step 4. Use slipknot cord to fasten the parachute bag mouth and pull the parachute cord to the outside of the wind tunnel.

Figure 10 shows the state before the wind blows after the parachute canopy is completed. 


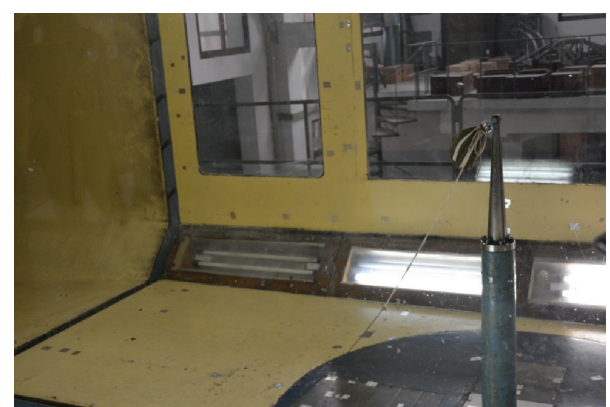

Figure 10: The states before winding after installing parachute canopy.

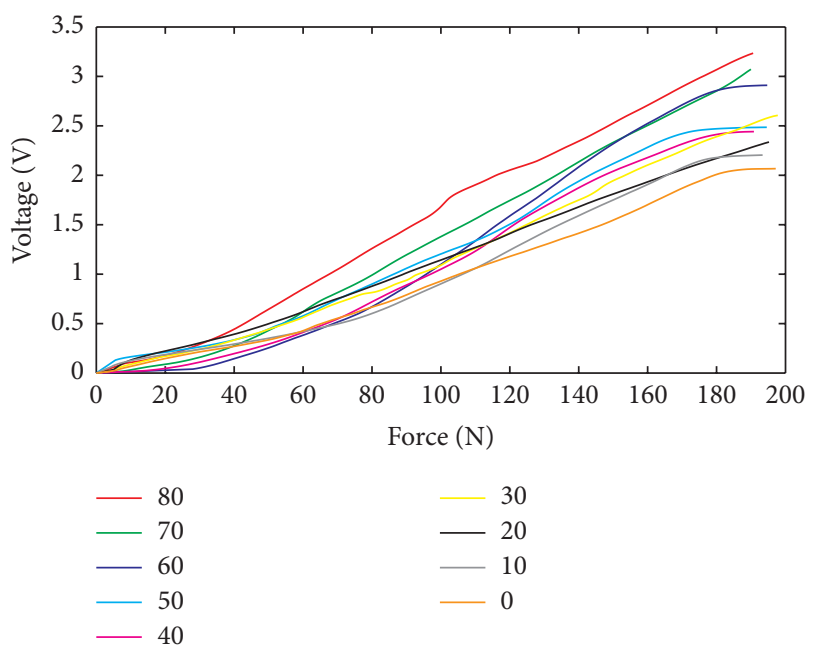

FIGURE 11: Stretch test data at different static intervals.

\section{Analysis and Conclusion}

6.1. Measurement of Aging Degree. Figure 11 shows the data of the sensor module at different intervals after the 80-day experiment.

As shown in Figure 12, the sensor module data changes with the time. However, the sensor performance changes to some extent. Although the performance of the sensor module changes slightly within a short period of time (fewer than 30 days), the performance changes a lot when the period is over 30 days.

6.2. Repeated Measurement. Figure 12 presents the data of the repeated experiments. As shown, only the 5th test has a relatively large variation. The differences between another 4 changes do not exceed $2 \%$. The sensor module test can be repeated less than 4 times.

6.3. Drop Experiment. Figure 13 shows the opening process of the parachute canopy. The drop experiment is under real opening from the bag to stabilized descent. The parachute inflates first, opens gradually, and enters a breathing process after opening completely.

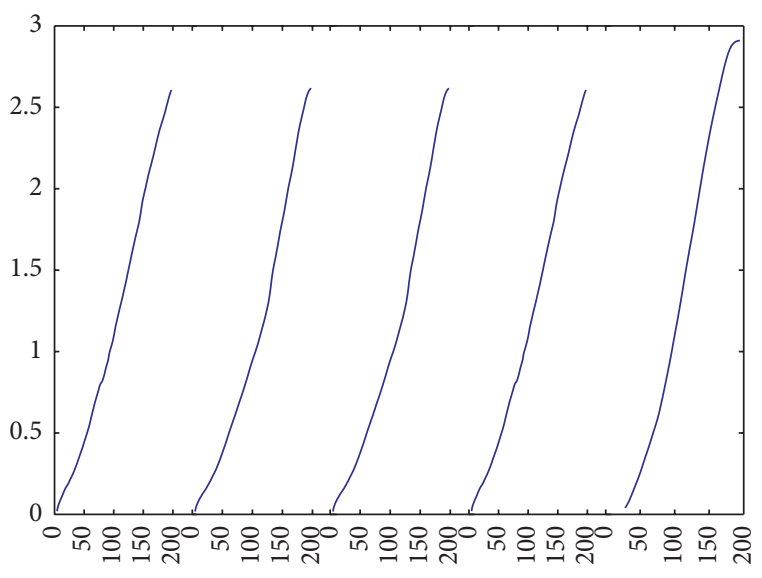

FIGURE 12: Results of repeated measurements for 5 times.

Figure 14 shows the collected data by the sensor module. (1) is the beginning phase; (2) is the inflating and opening phase, during which the parachute is opened completely and the data reaches the peak value and then enters phase (3), which is the breathing phase. In this period, the parachute keeps being open and closed. The stressed information is collected and can represent the stress characteristics of this phase. At last, the experiment goes to phase (4).

6.4. Wind Tunnel Experiment. According to the deployment of the sensor on the parachute surface, ID1\# and ID3\# are placed at the same latitude, which is $8 \mathrm{~cm}$ away from the center hole of the parachute; ID2\# and ID4\# are placed at the same latitude, which is $11 \mathrm{~cm}$ away from the center hole. The test is repeated 3 times at the wind speed of $30 \mathrm{~m} / \mathrm{s}$. The inflating process of the small parachute is shown in Figure 15 and the 3 groups of experiment results are shown in Figures 16,17 , and 18 , respectively.

According to the analysis of the above experimental results, the three peaks of sensor ID1\# are $140.1 \mathrm{~N}, 139.3 \mathrm{~N}$, and $139.9 \mathrm{~N}$; the three peaks of sensor ID3\# are $138.8 \mathrm{~N}, 139.1 \mathrm{~N}$, and $138.3 \mathrm{~N}$; the three peaks of sensor ID2\# are $109.2 \mathrm{~N}$, $107.4 \mathrm{~N}$, and $108.9 \mathrm{~N}$; the three peaks of sensor ID4\# are 108.3 N, 107.1 N, and 107.5 N. All the repeatability errors of the three repeatability experiments of each sensor are less than $1 \%$. The difference ratio of the sensors at the same latitude is less than $1.05 \%$.

From these three figures, the sensor can capture the stress change of the parachute canopy during the opening and inflating process of the parachute. In the opening process of the parachute, the stress reaches the peak at the parachute opening moment. Then it reaches the breathing peak and enters the circular breathing process. The sensor can sensitively and credibly reflect the canopy stress in the opening and inflating phase of the parachute.

6.5. Conclusion. According to the sensor performance experiments, the sensor can achieve a high repeatability within 30 days, which can properly reflect the stress on the tested fabric. Through the drop experiment and wind tunnel experiment, 

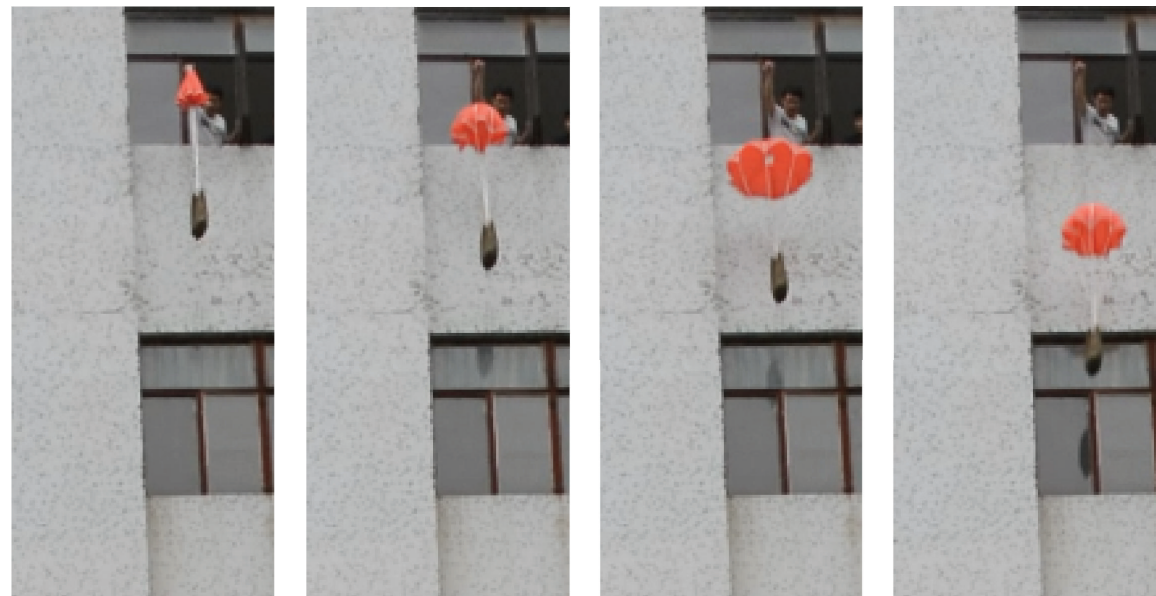

FIGURE 13: Opening process of the parachute canopy in the drop experiment.

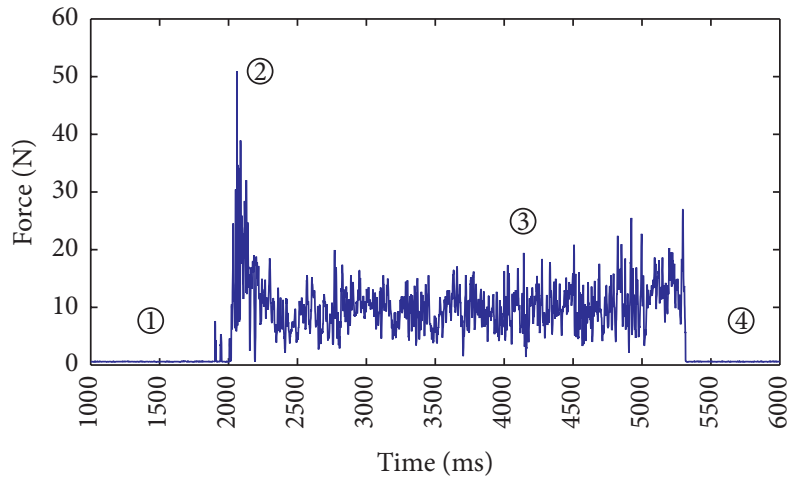

Figure 14: Parachute canopy stress in the drop experiment.

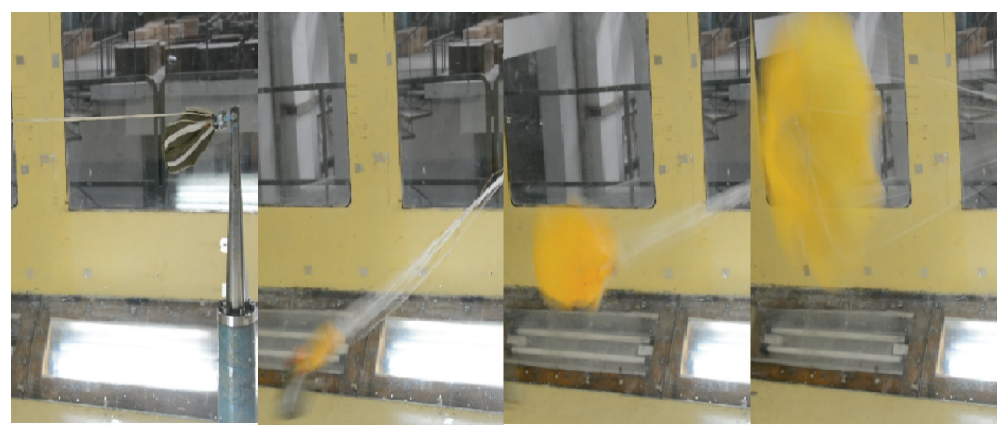

FIGURE 15: Opening of the parachute in the wind tunnel experiment.

the sensor can capture the stress change of the parachute canopy during the opening and inflating process of the parachute. In the opening process of the parachute, the stress reaches the peak at the parachute opening moment. Then it reaches the breathing peak and enters the circular breathing process. For repeatability experiments of the same parachute canopies, the sensor can sensitively and credibly reflect the canopy stress in the opening and inflating phase of the parachute.
The sensor module proposed in this paper can effectively overcome the problems of current methods for not compensating for factors that influence the experiment. The improved $\Omega$-type sensor has a better stress transmitting structure. The data collected by the full-bridge temperature compensating strain gauge, which is optimized through the auxiliary circuit, makes the data more reliable. The use of wireless means and convenient deployment of the sensor reduces the influence of the wired deployment. In further 


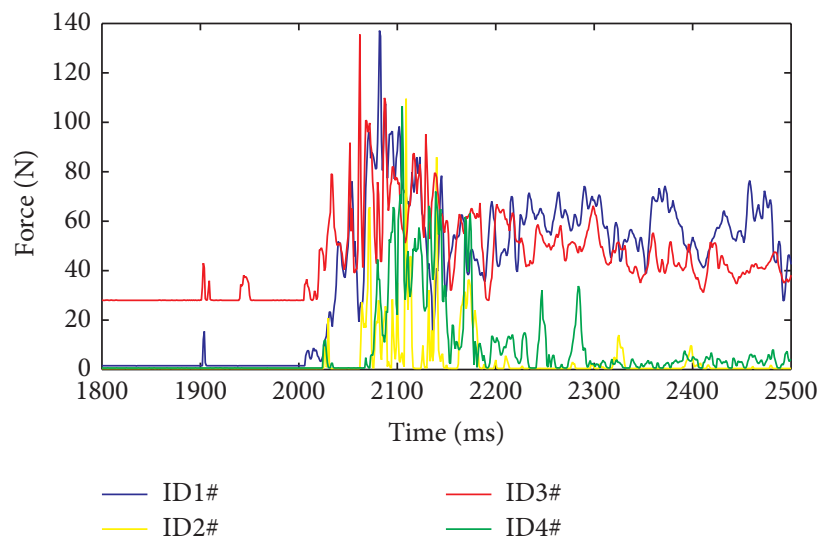

FIGURE 16: Experiment results of 544 circle flat parachute stress (first experiment).

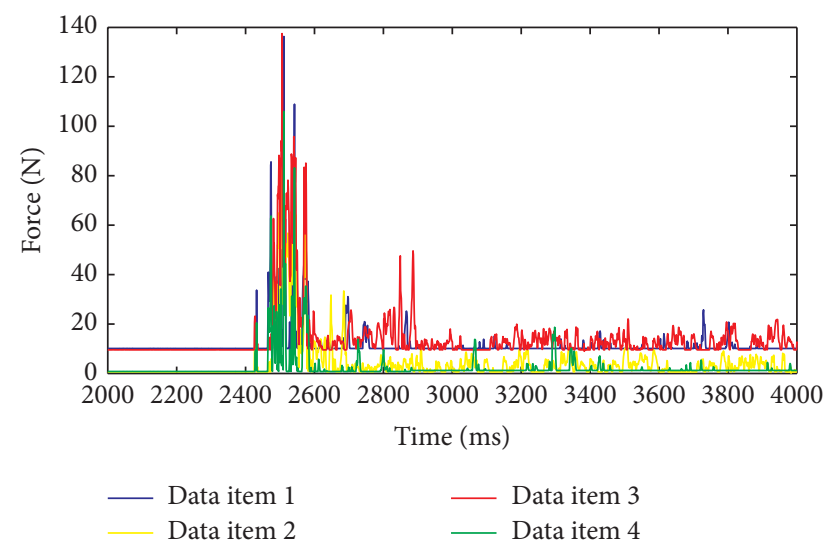

FIGURE 17: Experiment results of 544 circle flat parachute stress (second experiment).

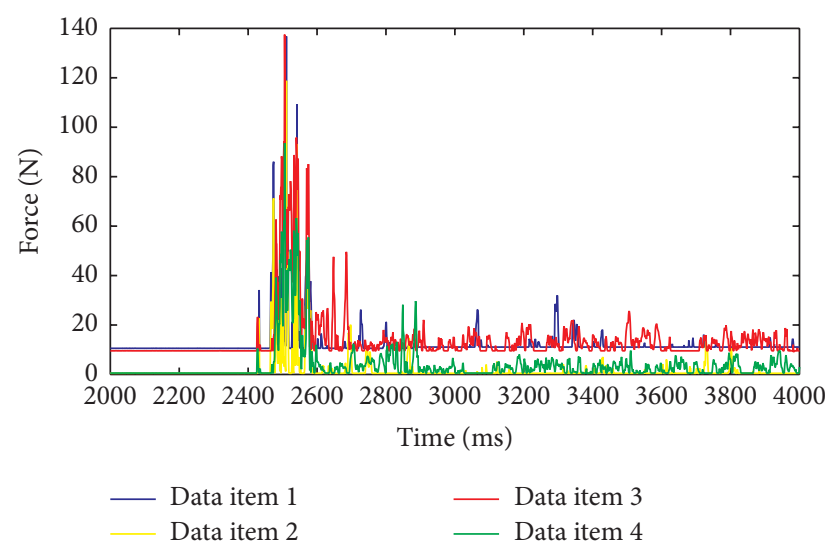

FIGURE 18: Experiment results of 544 circle flat parachute stress (third experiment).

researches, drop experiments will be conducted to verify the sensor module. Additionally, the sensor module structure will be further improved to satisfy the demands under bad application conditions.

\section{Competing Interests}

The authors declare that they have no competing interests.

\section{Acknowledgments}

This work is supported by the National Natural Science Foundation of China (General Program) under Grant no. 61572253, the National Natural Science Foundation for Youth of China under Grant no. 61202351, the National Postdoctoral Fund under Grant no. 2011M500124, and the Fundamental Research of Nanjing University of Aeronautics and Astronautics under Grant no. NS2012133.

\section{References}

[1] C. Cochrane, M. Lewandowski, and A. V. Koncar, "A flexible strain sensor based on a conductive polymer composite for in situ measurement of parachute canopy deformation," Sensors, vol. 10, no. 9, pp. 8291-8303, 2010.

[2] L. Yu, H. Cheng, Y. Zhan, and S. Li, "Study of parachute inflation process using fluid-structure interaction method," Chinese Journal of Aeronautics, vol. 27, no. 2, pp. 272-279, 2014.

[3] H. Cheng, U. Y. Li, and Y. I. N. Zhu-wei, "A new method of complicated folded fabric modeling," Journal of Harbin Institute of Technology, vol. 19, no. 2, pp. 43-46, 2012.

[4] Q. Shi, D. Reasor, Z. Gao, X. Li, and R. D. Charles, "On the verification and validation of a spring fabric for modeling parachute inflation," Journal of Fluids and Structures, vol. 58, pp. 20-39, 2015.

[5] K. Takizawa, T. Spielman, C. Moorman, and T. E. Tezduyar, "Fluid-structure interaction modeling of spacecraft parachutes for simulation-based design," Journal of Applied Mechanics, vol. 79, no. 1, Article ID 010907, 2012.

[6] K. Takizawa, S. Wright, C. Moorman, and T. E. Tezduyar, "Fluid-structure interaction modeling of parachute clusters," International Journal for Numerical Methods in Fluids, vol. 65, no. 1-3, pp. 286-307, 2011.

[7] I. M. Khan and K. S. Anderson, "A logarithmic complexity divide-and-conquer algorithm for multi-flexible-body dynamics including large deformations," Multibody System Dynamics, vol. 34, no. 1, pp. 81-101, 2015. 
[8] I. M. Khan, W. Ahn, K. S. Anderson, and S. De, "A logarithmic complexity floating frame of reference formulation with interpolating splines for articulated multi-flexible-body dynamics," International Journal of Non-Linear Mechanics, vol. 57, pp. 146153, 2013.

[9] T. Zheng and D.-G. Zhang, "Limitations of MSC. ADAMS for high-speed and large deformation problems of rigid-flexible coupling systems," Journal of Nanjing University of Science and Technology, vol. 36, no. 6, pp. 993-998, 2012.

[10] H. G. Heinrich and D. P. Saari, "Parachute canopy stress measurements at steady state and during inflation," Journal of Aircraft, vol. 15, no. 8, pp. 534-539, 1978.

[11] C. Cochrane, V. Koncar, M. Lewandowski, and C. Dufour, "Design and development of a flexible strain sensor for textile structures based on a conductive polymer composite," Sensors, vol. 7, no. 4, pp. 473-492, 2007.

[12] M. Tang and M. Zhu, "A measurement of flexible filled structure stress and strain of new type of sensor system," in 23th National Space Exploration Abstract Set of Academic Exchange, 2010.

[13] J. Bazin and T. D. Fields, "Validation and flight testing of a wireless load distribution measuring system," in Proceedings of the 23rd AIAA Aerodynamic Decelerator Systems Technology Conference, Aerodynamic Decelerator Systems Technology Conferences, AIAA 2015-2120, Daytona Beach, Fla, USA, 2015.

[14] S. A. Khan, T. Islam, and G. Husain, "Artificial neural network based online sensor calibration and compensation," International Journal of Computing, vol. 6, no. 3, pp. 74-78, 2014.

[15] R. Song, X. Chen, C. Shen, and H. Zhang, "Modeling FOG drift using back-propagation neural network optimized by artificial fish swarm algorithm," Journal of Sensors, vol. 2014, Article ID 273043, 6 pages, 2014. 


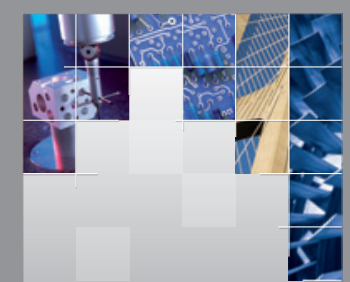

\section{Enfincering}
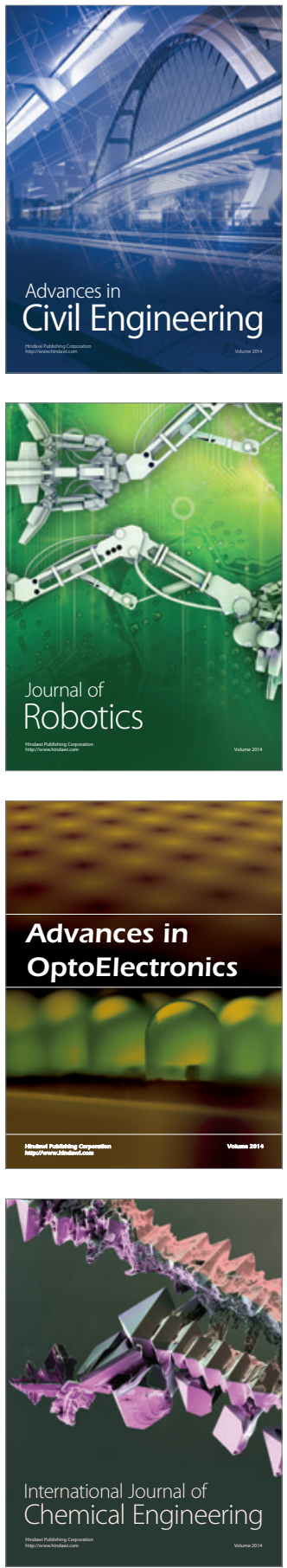

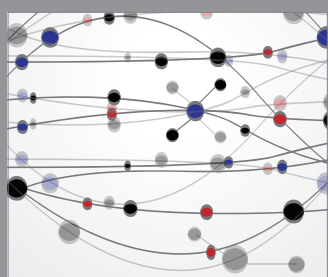

The Scientific World Journal

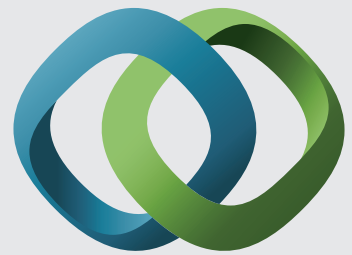

\section{Hindawi}

Submit your manuscripts at

http://www.hindawi.com
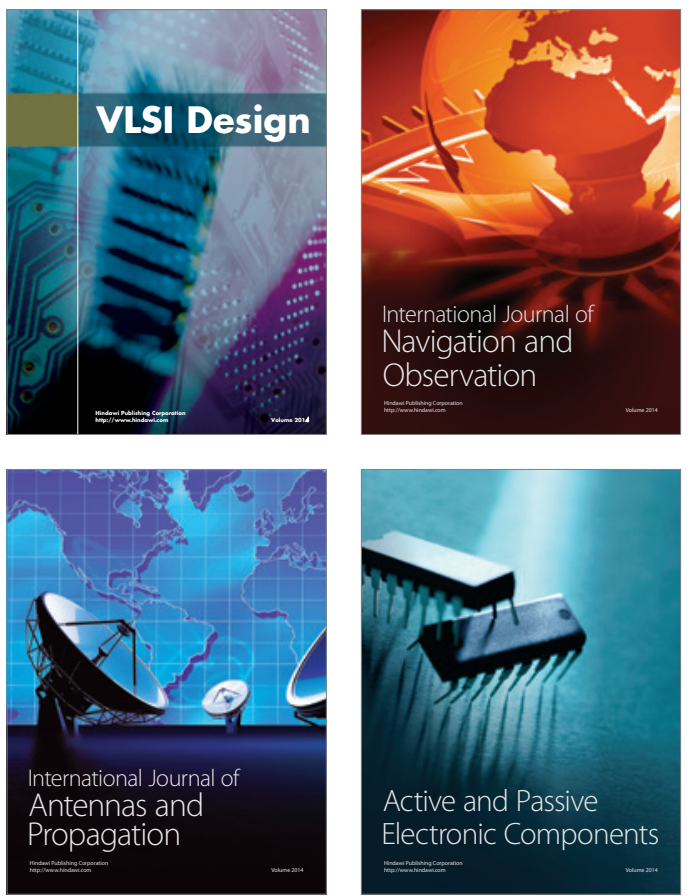
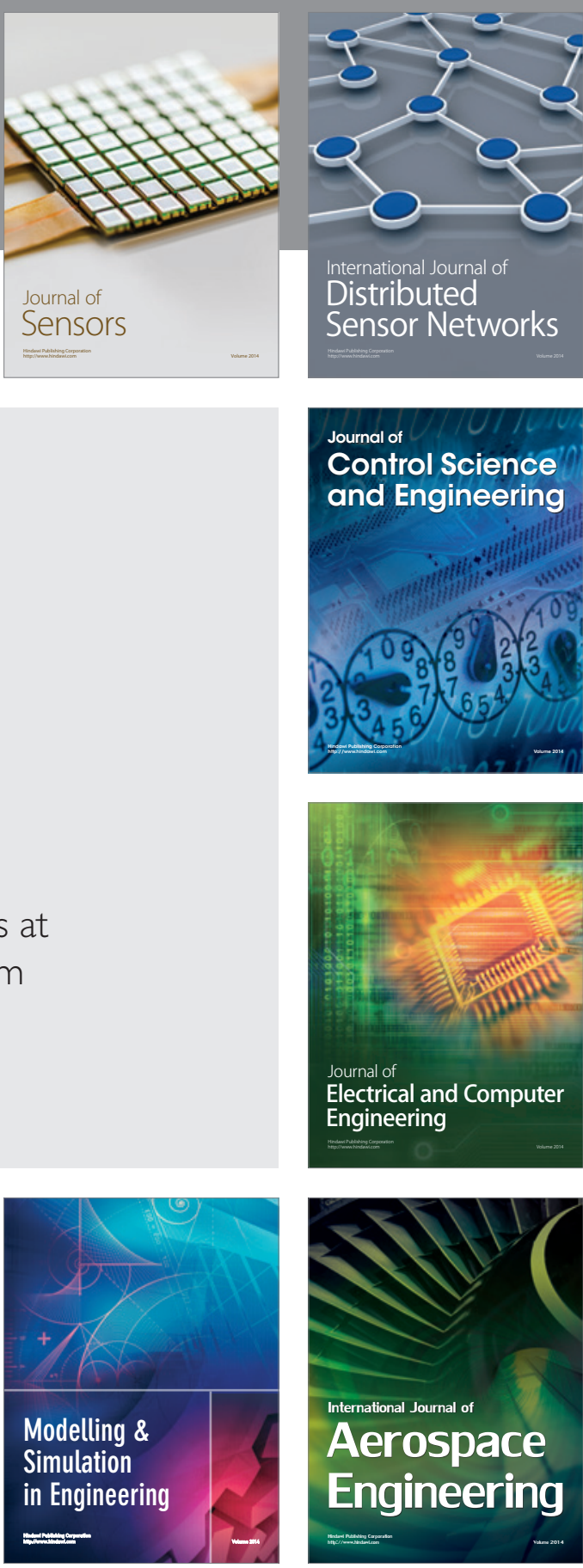

International Journal of

Distributed

Sensor Networks

Journal of

Control Science

and Engineering
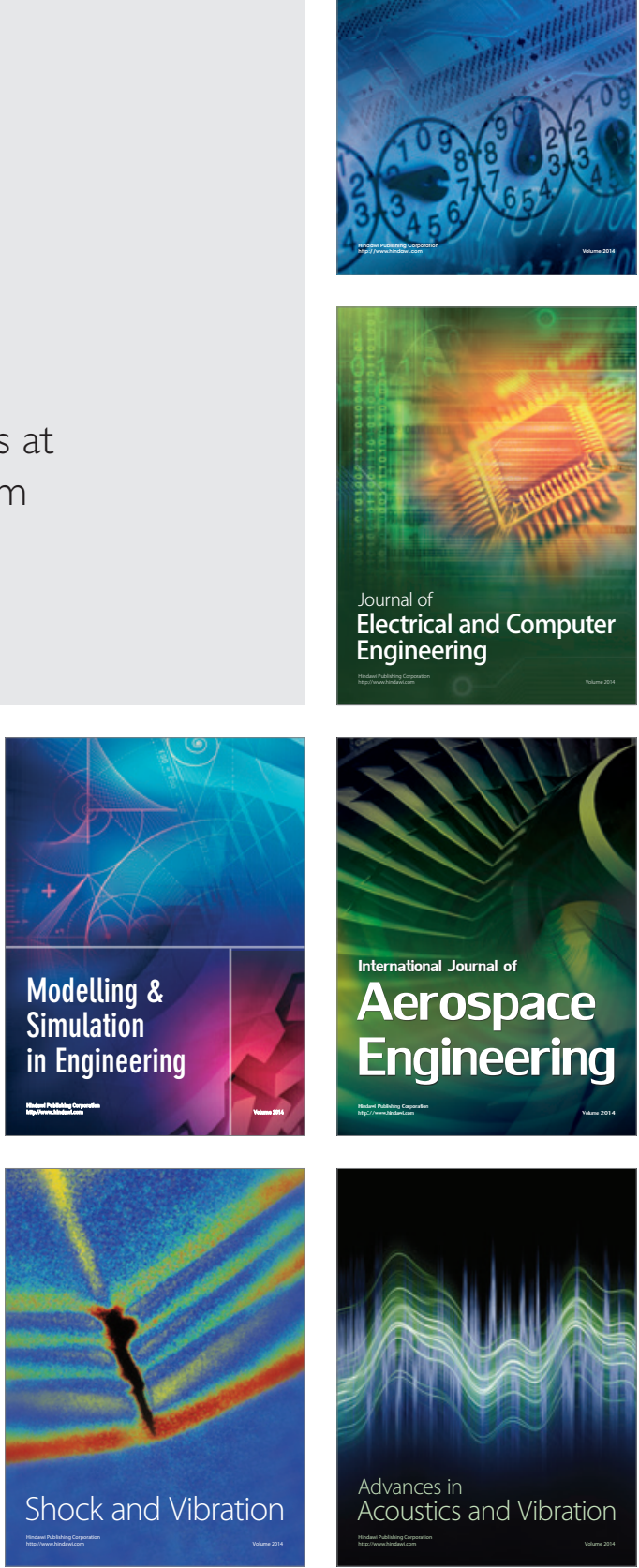